\title{
A rational two-step approach to KRAS mutation testing in colorectal cancer using high resolution melting analysis and pyrosequencing
}

Elisabeth Mack ${ }^{1}$, Kathleen Stabla ${ }^{1}$, Jorge Riera-Knorrenschild ${ }^{1}$, Roland Moll ${ }^{2}$, Andreas Neubauer ${ }^{1}$ and Cornelia Brendel ${ }^{1 *}$

\begin{abstract}
Background: KRAS mutation testing is mandatory in the management of metastatic colorectal cancer prior to treatment with anti-EGFR antibodies as patients whose tumors express mutant KRAS do not benefit from these agents. Although the U.S. Food and Drug Administration has recently approved two in-vitro diagnostics kits for determination of KRAS status, there is generally no consensus on the preferred method and new tests are continuously being developed. Most of these techniques focus on the hotspot mutations at codons 12 and 13 of the KRAS gene.

Methods: We describe a two-step approach to KRAS codon 12/13 mutation testing involving high resolution melting analysis (HRM) followed by pyrosequencing using the Therascreen KRAS Pyro kit (Qiagen) of only those samples that are not clearly identified as KRAS wildtype or mutant by HRM. First, we determined KRAS status in a panel of 61 colorectal cancer samples using both methods to compare technical performance and concordance of results. Subsequently, we evaluated practicability and costs of our concept in an independent set of 120 colorectal cancer samples in a routine diagnostic setting.

Results: HRM and pyrosequencing appeared to be equally sensitive, allowing for clear detection of mutant alleles at a mutant allele frequency $\geq 12.5 \%$. Pyrosequencing yielded more exploitable results due to lower input requirements and a lower rate of analysis failures. KRAS codon 12/13 status was called concordantly for $98.2 \%$ (56/ 57) of all samples that could be successfully analysed by both methods and $100 \%$ (19/19) of samples that were identified mutant by HRM. Reviewing the actual effort and expenses for KRAS mutation testing in our laboratory revealed, that the selective use of pyrosequencing for only those samples that could not be analysed by HRM increased the fraction of valid results from $87.5 \%$ for HRM alone to $99.2 \%(119 / 120)$ while allowing for a net reduction of operational costs of $>75 \%$ compared to pyrosequencing alone.
\end{abstract}

Conclusions: Combination of HRM and pyrosequencing in a two-step diagnostic procedure constitutes a reliable and economic analysis platform for KRAS mutation testing in colorectal cancer in a clinical setting.

Keywords: KRAS mutation, Colorectal cancer, High resolution melting analysis, Pyrosequencing

\footnotetext{
* Correspondence: brendelc@staff.uni-marburg.de

${ }^{1}$ Klinik für Hämatologie, Onkologie und Immunologie, Universitätsklinikum

Gießen und Marburg, Standort Marburg, Philipps-Universität Marburg,

Baldingerstraße, Marburg, Germany

Full list of author information is available at the end of the article
} 


\section{Background}

The anti EGFR-antibodies cetuximab and panitumumab represent well-established treatments for metastatic colorectal cancer (CRC), the third most prevalent cancer entity and fourth most common cause of cancer-related death around the world [1, 2]. Several studies have shown KRAS status to predict outcome under these anti-EGFR targeting agents, with beneficial effects being seen only in patients whose tumors express wildtype (WT) KRAS [3-8]. Thus, testing for KRAS mutations, which are found in approximately $40 \%$ of colorectal cancers, has become routine in the management of metastatic CRC (mCRC) prior to cetuximab or panitumumab treatment $[9,10]$ and is even required by the responsible regulatory agencies. Notably, current standards regarding oncogenic Ras mutation analysis in $\mathrm{mCRC}$ issued by the U.S Food and Drug Administration (FDA) require determination of KRAS status by an FDAapproved test, while the European Medical Agency (EMA) just states application of validated methods by an experienced laboratory [11-15]. Currently available FDA-approved companion diagnostic devices for cetuximab (Erbitux) and panitumumab (Vectibix) comprise the Cobas KRAS Mutation Test (Roche) and Therascreen KRAS RGQ PCR Kit (Qiagen) [16]. Besides these and other commercially available kits, the spectrum of methods for KRAS mutation testing encompasses multiple PCR-derived and sequencing-based techniques. Of note, most of the previously established assays for KRAS mutation detection focus on the hotspot mutations involving codons 12 and 13, which account for $>95 \%$ of Ras mutations in CRC [10]. The advantages and limitations of selected methods have been repeatedly evaluated comparatively [17-22], however, beyond the FDAguideline, there is no consensus on the preferred approach to investigate $K R A S$ status in routine molecular pathological diagnostics [23]. Given the high incidence of CRC resulting in high demand for KRAS mutation testing, an ideal diagnostic assay for this purpose not only needs to be sufficiently sensitive and specific, but, for socio-economic reasons, also should be time- and cost-effective. Therefore, we developed a two-step procedure for KRAS mutation testing including high resolution melting analysis (HRM) followed by pyrosequencing of only those samples that are not clearly identified as KRAS WT or mutant by HRM. HRM is a one-tube qPCR-based technique for DNA-variant detection. The method utilizes alterations in the melting behavior of double-stranded DNA fragments that are conferred by nucleotide exchanges. Melting of qPCR amplicons is monitored in real time using a suitable qPCR instrument capable of time-dense data aquisition and a saturating DNA-intercalating fluorescent dye that does not redistribute during the melting step [24].
Pyrosequencing is a sequencing-by-synthesis approach that involves sequential addition of dNTPs and recording incorporation of a nucleotide based on a light signal that is generated by sulfurylase-catalyzed conversion of the released pyrophosphate to ATP and a subsequent luciferase reaction [25]. Here, we applied a previously described HRM-assay [20] and the Therascreen KRAS Pyro kit (Qiagen) for detection of KRAS codon 12/13 mutations. First we comparatively analysed $K R A S$ status in a panel of 61 colon cancer samples to determine sensitivity, specificity, technical performance and concordance of results of the two methods. Subsequently, we evaluated our two-step approach in the routine setting of our molecular diagnostics laboratory. In summary, we present a reliable, time- and cost-effective operational concept for KRAS mutation testing prior to antiEGFR antibody treatment in mCRC.

\section{Methods}

\section{Tumor samples, control cell lines and DNA isolation}

The colorectal cancer samples reported on in this study were obtained from patients with metastatic colorectal cancer (UICC IV) at the University Hospital Marburg, Germany and analysed in a routine diagnostic setting. Tissue samples were fixed, paraffin-embedded, sectioned, hematoxylin-eosin stained and deparaffinated using standard procedures. Tissue sections were reviewed by an experienced pathologist (RM) to establish the diagnosis and to mark regions for microdissections. Microdissection of tumor cells was performed from deparaffinated sections using a scalpel. DNA was isolated from microdissected samples using the QiaAmp DNA Mini kit (Qiagen) as recommended by the manufacturer. KRAS mutant cell lines PL45 (pancreatic adenocarcinoma) and RPMI 8226 (multiple myeloma) were obtained from ATCC and cultured according to standard cell culture methods. Positive control DNA for HRM analyses was isolated from these cell lines using the QiaAmp DNA Mini kit. WT control DNA was extracted from peripheral blood of healthy donors from whom informed consent had been obtained (WT control) with the QiaAmp DNA Mini kit. DNA concentrations were measured using a Nanodrop 1000 spectrophotometer (Peqlab).

\section{High resolution melting analysis}

For HRM analysis, a 92 bp amplicon spanning exons 2 and 3 of the KRAS gene was amplified from $60 \mathrm{ng}$ (or less) of sample DNA using the primers KRAS-92_F $5^{\prime}$ ttataaggcctgctgaaaatgactgaa-3' and KRAS-92_R $5^{\prime}$-tgaattagctgtatcgtcaaggcact-3' [20], the DNA-intercalating dye SYTO 9 (Thermo) in a final concentration of $5 \mu \mathrm{M}$ and Platinum Taq polymerase (Thermo). Amplification and melting analysis was performed on a Rotor Gene 6000 instrument (Corbett Life Sciences) under the following temperature conditions: one cycle $95{ }^{\circ} \mathrm{C} / 2 \mathrm{~min}, 40$ cycles 
$95{ }^{\circ} \mathrm{C} / 15 \mathrm{sec}-67.5{ }^{\circ} \mathrm{C} / 15 \mathrm{sec}-72{ }^{\circ} \mathrm{C} / 15 \mathrm{sec}$, one cycle $95{ }^{\circ} \mathrm{C} / 1 \mathrm{sec}$, pre-melt conditioning at $72{ }^{\circ} \mathrm{C} / 90 \mathrm{sec}$, HRM-ramp from $72{ }^{\circ} \mathrm{C}$ to $95{ }^{\circ} \mathrm{C}$ rising at $0.2{ }^{\circ} \mathrm{C}$ per step/wait 2 sec each step. Controls in each HRM run included a no-template-control, a WT control (gDNA from healthy donor) and two mutation controls (gDNA from the cell lines RPMI 8226, KRAS codon 12 GGT $\rightarrow$ GCT/ heterozygous, corresponding to G12A and PL45, KRAS codon 12 GGT $\rightarrow$ GAT/heterozygous, corresponding to G12D). All HRM assays were performed in quadruplicate.

\section{Pyrosequencing}

Pyrosequencing of the KRAS codon 12/13 region was performed using the Therascreen KRAS Pyro Kit (Qiagen) as recommended by the manufacturer. 2 ng of DNA were used per analysis. PCR amplification of the target region was performed on a T-100 thermocycler (Biorad). For the pyrosequencing reaction on the PyroMark Q24 platform (Qiagen), amplicons were immobilized to the wells of a PyroMark Q24 plate using streptavidin high performance beads (GE Healthcare). Pyrosequencing results were analysed using the PyroMark Q24 software version 2.0 with the Therascreen KRAS Pyro-plugin report, which already incorporated the thresholds for mutation calls (detection limit for the mutation (LOD) $+3 \%$ ).

\section{Statistical analysis}

HRM and pyrosequencing results were compared by contingency table analysis test using GraphPad Prism 5 software (GraphPad). Technical performance (1st run success vs. 1st run failure) was evaluated by two-sided Fisher's exact test at a significance level of $5 \%$. The agreement between HRM and pyrosequencing results was quantified by kappa using the appropriate Graphpad Prism online calculator (http://graphpad.com/quickcalcs/kappa2).

\section{Results}

\section{Sensitivity of HRM and pyrosequencing}

In order to test whether pyrosequencing allows for $K R A S$ mutation detection with at least equal sensitivity compared to HRM, we analysed serial dilutions of DNA from a KRAS mutant cell line (PL45, codon 12 GGT $\rightarrow$ GAT heterozygous mutation) in WT DNA by both HRM and pyrosequencing. For HRM, we found, that the presence of KRAS mutant DNA in the sample was clearly reflected by a shifted or skewed melting curve for

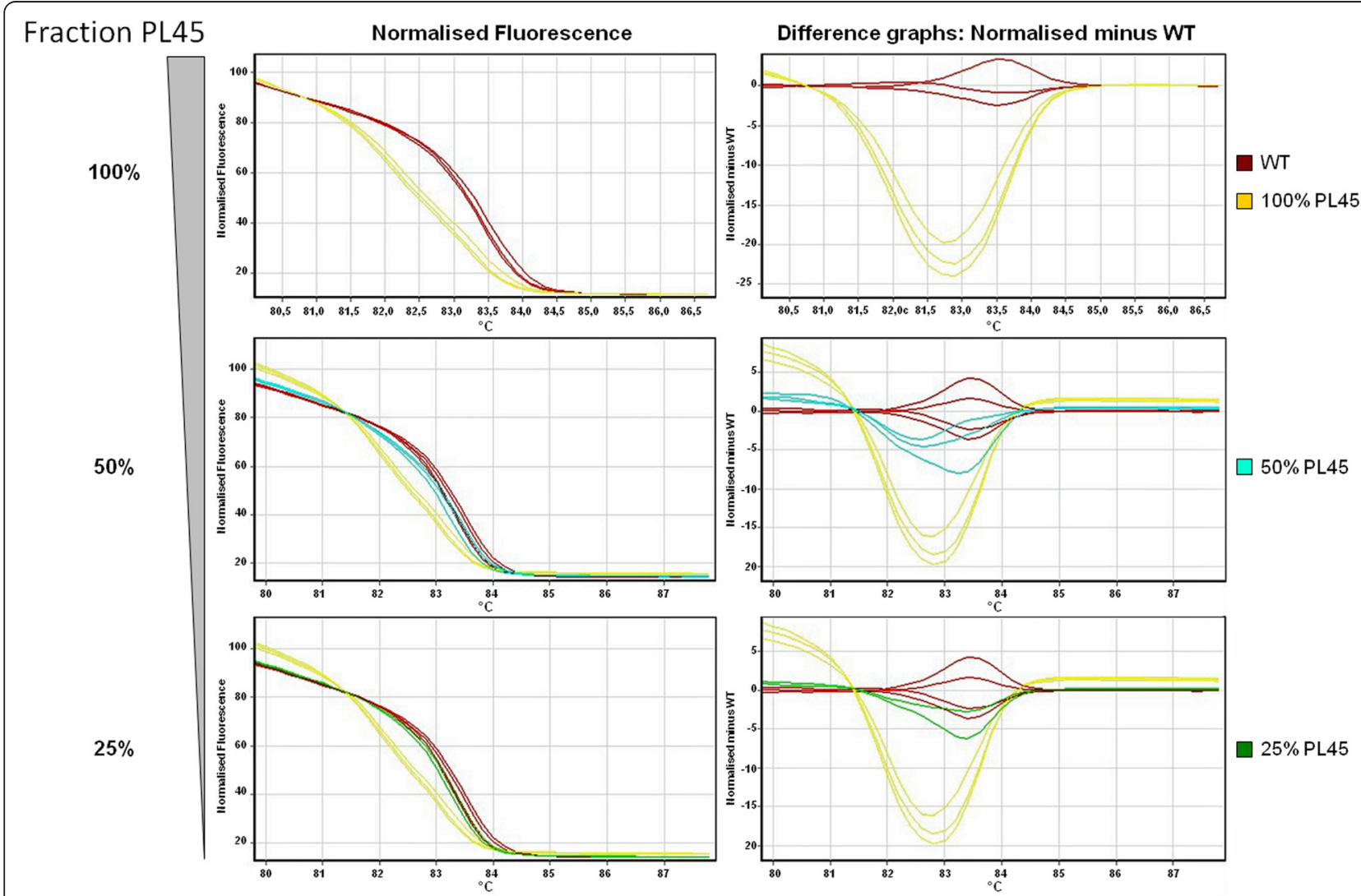

Fig. 1 Sensitivity of HRM. Dilutions of genomic DNA from the KRAS mutant cell line PL45 (codon 12 GGT $\rightarrow$ GAT, heterozygous mutation) in WT genomic DNA was analysed by HRM. Normalised fluorescence and difference graphs are indicated. Clear discrimination of WT and mutant amplicons is possible using either graph if the fraction of PL45-DNA in the sample exceeds $25 \%$, corresponding to a mutant allele frequency of $12.5 \%$ 
a fraction of PL45-DNA exceeding $25 \%$, which corresponded to a mutant allele frequency of $12.5 \%$ (Fig. 1). Similarly, pyrosequencing definitely yielded a mutation if the sample contained $\geq 25 \%$ PL45-DNA. On the other hand, samples with 5-10\% cell line DNA were indicated to exhibit a potential low level mutation as the mutant allele frequency was quantified below the threshold for accurate WT/mutant discrimination for the G12D mutation (LOD + $3 \%$; LOD = 2,2 \%) for both the 5 and $10 \%$ samples (Fig. 2). Thus, HRM and pyrosequencing appeared to be equally sensitive methods for the detection of KRAS codon 12/13 mutations.

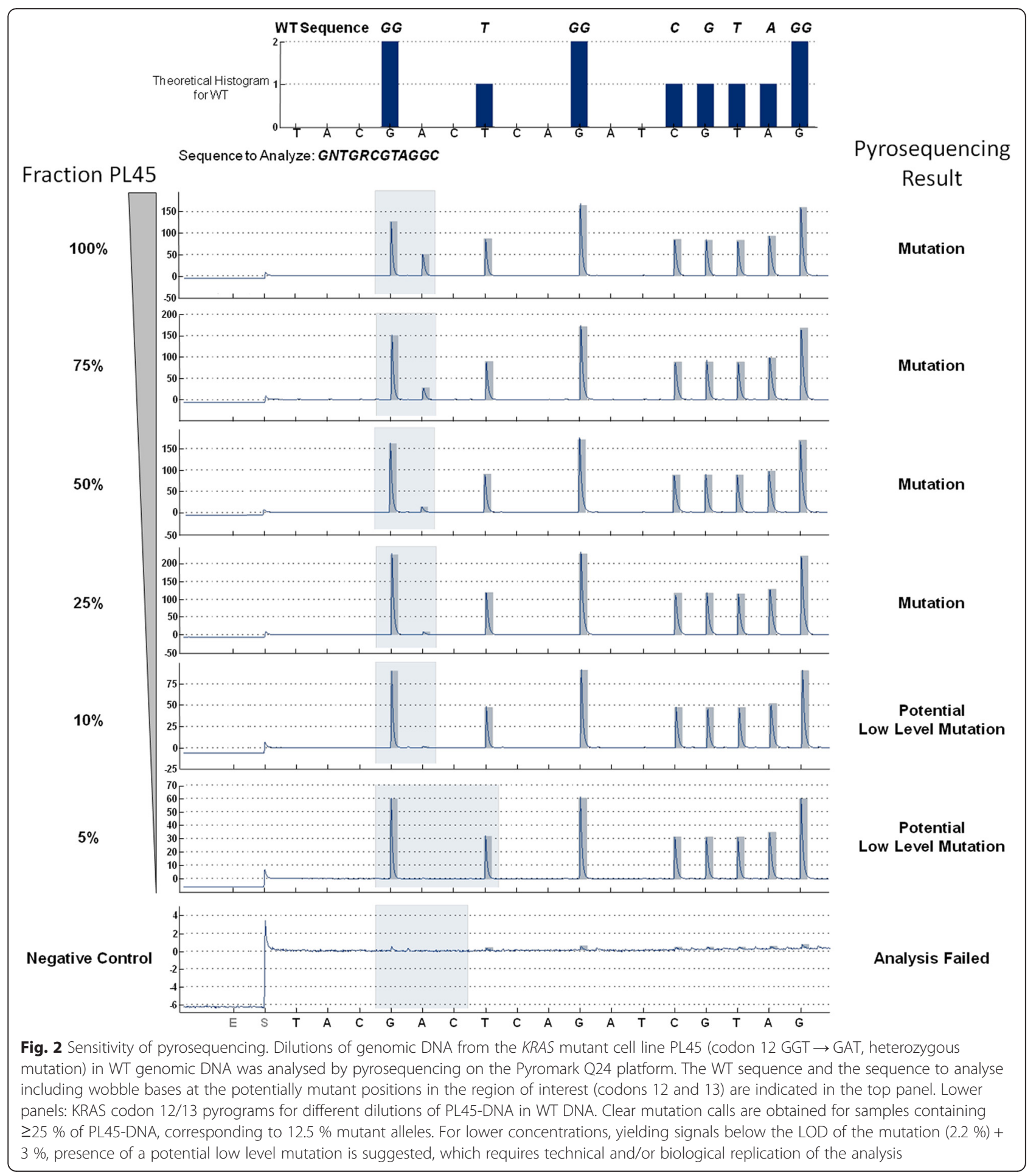


Table 1 KRAS codon 12/13 status by HRM and pyrosequencing in 61 CRC samples

\begin{tabular}{|c|c|c|c|c|c|c|c|c|}
\hline \multirow[b]{3}{*}{ Sample } & \multirow[b]{3}{*}{$\begin{array}{l}\text { CDNA } \\
{[n g / \mu l]}\end{array}$} & \multicolumn{2}{|l|}{ HRM } & \multicolumn{5}{|c|}{ Pyrosequencing } \\
\hline & & \multirow[b]{2}{*}{ Run 1} & \multirow[b]{2}{*}{ Run 2} & \multicolumn{2}{|l|}{ Run 1} & \multicolumn{2}{|l|}{ Run 2} & \multirow[b]{2}{*}{$\begin{array}{l}\text { Final } \\
\text { result }\end{array}$} \\
\hline & & & & Result & $\begin{array}{l}\% \text { mut. } \\
\text { Alleles }\end{array}$ & Result & $\begin{array}{l}\% \text { mut. } \\
\text { Alleles }\end{array}$ & \\
\hline 1 & 11 & failed & $W T^{a}$ & WT & & & & WT \\
\hline 2 & 31 & $W T^{a}$ & & WT & & & & WT \\
\hline 3 & 10 & $W T^{a}$ & & $\mathrm{G} 12 \mathrm{C}$ & 13.4 & & & mut \\
\hline 4 & 93 & $W T^{a}$ & & WT & & & & WT \\
\hline 5 & 26 & $W T^{a}$ & & WT & & & & WT \\
\hline 6 & 27 & $W T^{a}$ & & WT & & & & WT \\
\hline 7 & 10 & $W T^{a}$ & & WT & & & & WT \\
\hline 8 & 43 & mut & & G13D & 73.9 & & & mut \\
\hline 9 & 85 & failed & WT & WT & & & & WT \\
\hline 10 & N/A & mut & & G13D & 44.3 & & & mut \\
\hline 11 & N/A & failed & & G12V & 2.6 & & & $W T^{b}$ \\
\hline 12 & N/A & WT & & WT & & & & WT \\
\hline 13 & N/A & mut & & G12V & 41.9 & & & mut \\
\hline 14 & 126 & mut & & failed & & G12D & 65.7 & mut \\
\hline 15 & 133 & mut & & G12D & 74.1 & & & mut \\
\hline 16 & 97 & mut & & G13D & 52.8 & & & mut \\
\hline 17 & 47 & failed & WT & WT & & & & WT \\
\hline 18 & 14 & failed & WT & WT & & & & WT \\
\hline 19 & 44 & $W T^{a}$ & & WT & & & & WT \\
\hline 20 & 20 & failed & $W T^{a}$ & WT & & & & WT \\
\hline 21 & N/A & failed & & WT & & & & WT \\
\hline 22 & 138 & mut & & G12V & 12.9 & & & mut \\
\hline 23 & 325 & mut & & G12D & 56.1 & & & mut \\
\hline 24 & 140 & $W T^{a}$ & & WT & & & & WT \\
\hline 25 & 7 & mut & & $\mathrm{G} 12 \mathrm{C}$ & 61.2 & & & mut \\
\hline 26 & 4 & $W T^{a}$ & & WT & & & & WT \\
\hline 27 & 27 & $W T^{a}$ & & WT & & & & WT \\
\hline 28 & 13 & $W T^{a}$ & & WT & & & & WT \\
\hline 29 & 207 & mut & & G12D & 54.5 & & & mut \\
\hline 30 & 10 & failed & WT & G12V & 1.5 & & & $W T^{b}$ \\
\hline 31 & 54 & $W T^{a}$ & & WT & & & & WT \\
\hline 32 & 120 & mut & & G12V & 29.2 & & & mut \\
\hline 33 & 33 & failed & mut & $\mathrm{G} 12 \mathrm{C}$ & 33.5 & & & mut \\
\hline 34 & N/A & mut & & $\mathrm{G} 12 \mathrm{C}$ & 71.4 & & & mut \\
\hline 35 & N/A & $W T$ & & WT & & & & WT \\
\hline 36 & N/A & failed & & WT & & & & WT \\
\hline 37 & 67 & $W T^{a}$ & & WT & & & & WT \\
\hline 38 & 137 & mut & & $\mathrm{G} 12 \mathrm{C}$ & 76.7 & & & mut \\
\hline 39 & 63 & mut & & $\mathrm{G} 12 \mathrm{~A}$ & 56 & & & mut \\
\hline 40 & 13 & $W T^{a}$ & & WT & & & & WT \\
\hline 41 & 113 & $W T^{a}$ & & WT & & & & WT \\
\hline
\end{tabular}

Table 1 KRAS codon 12/13 status by HRM and pyrosequencing in 61 CRC samples (Continued)

\begin{tabular}{|c|c|c|c|c|c|}
\hline 42 & 82 & mut & $\mathrm{G} 12 \mathrm{C}$ & 75.4 & mut \\
\hline 43 & 39 & WT & WT & & WT \\
\hline 44 & 7 & $W T^{a}$ & G12S & 2 & $W T^{b}$ \\
\hline 45 & 23 & $W T^{a}$ & WT & & WT \\
\hline 46 & 24 & failed $^{a}$ & G13D & 3.5 & $W T^{b}$ \\
\hline 47 & 9 & $W T^{a}$ & WT & & WT \\
\hline 48 & 34 & $W T^{a}$ & G12S & 2 & $W T^{b}$ \\
\hline 49 & 25 & $W T^{a}$ & WT & & WT \\
\hline 50 & 17 & WT & WT & & WT \\
\hline 51 & 5 & $W T^{a}$ & WT & & WT \\
\hline 52 & 29 & $W T^{a}$ & WT & & WT \\
\hline 53 & 31 & mut & G12D & 71.3 & mut \\
\hline 54 & 68 & WT & WT & & WT \\
\hline 55 & 93 & mut & G12D & 74.2 & mut \\
\hline 56 & 221 & WT & WT & & WT \\
\hline 57 & 83 & WT & WT & & WT \\
\hline 58 & N/A & $W T^{a}$ & G12V & 1.2 & $W T^{b}$ \\
\hline 59 & 35 & mut & G12D & 83.3 & mut \\
\hline 60 & N/A & WT & WT & & WT \\
\hline 61 & 37 & $W T^{a}$ & WT & & WT \\
\hline
\end{tabular}

a Skewed HRM curve

b LOD/threshold for potential low level mutation (cf. Therascreen KRAS Pyro Kit handbook version 1, July 2011): G12D $2.2 \% / 5.2 \%$, G12V $1.0 \% / 4.0 \%$, G12C $2.1 \% / 5.1 \%$, G12S $1.9 \% / 4.9 \%$, G13D $1.9 \% / 4.9 \%$

Technical reliability of HRM and pyrosequencing

To further assess the suitability of pyrosequencing to serve as a backup-assay allowing for accurate diagnosis of KRAS mutation status in case of failed HRM analysis, we investigated $K R A S$ status of 61 colorectal cancer samples by both HRM and pyrosequencing and compared the two methods with regard to their technical performance and concordance of results. In a first run of HRM analysis, 11/61 samples (18.0\%) could not be analysed due to PCR-failures or ambiguous melting curves (Table 1). Repetition of the assay for seven samples, which most likely had been compromised technically, allowed for assigning KRAS mutation status in all cases. The remaining four samples were directly subjected to pyrosequencing without a second round of HRM analysis. Indeed, KRAS status could each be determined, although one sample yielded a potential low level mutation. Of the 57 samples that could be definitely classified as KRAS WT or mutant by HRM, 26 WT samples (45.6\% of all samples/68.4\% of WT samples) yielded skewed HRM curves, which, however, did not prevent establishment of a diagnosis (Tables 1 and 2). Moreover, we noted that low DNA content of the samples below 
Table 2 Comparison of HRM and pyrosequencing results in 61 CRC samples

\begin{tabular}{|c|c|c|c|c|c|c|}
\hline Summary of Results & \multicolumn{2}{|c|}{ Run 1} & \multicolumn{2}{|c|}{ Run 2} & \multicolumn{2}{|c|}{ Summary } \\
\hline HRM & $n$ & $\%$ & $n$ & $\%$ & $n$ & $\%$ \\
\hline Number of samples & 61 & 100.0 & 7 & $100.0(11.5)$ & 61 & 100.0 \\
\hline Analysis passed & 50 & 82.0 & 7 & 100.0 & 57 & 93.4 \\
\hline WT (total) & 32 & 64.0 & 6 & 85.7 & 38 & 66.7 \\
\hline WT (skewed HRM curve) & 24 & 75.0 & 2 & 33.3 & 26 & 68.4 \\
\hline Mutant (total) & 18 & 36.0 & 1 & 14.3 & 19 & 33.3 \\
\hline Mutant (skewed HRM curve) & 0 & & 0 & & 0 & \\
\hline Analysis failed & 11 & 18.0 & 0 & & & \\
\hline Pyrosequencing & $n$ & $\%$ & $n$ & $\%$ & $\mathrm{n}$ & $\%$ \\
\hline Number of samples & 61 & 100.0 & 1 & $100.0(1.6)$ & 61 & 100.0 \\
\hline Analysis passed & 60 & 98.4 & 1 & 100.0 & 61 & 100.0 \\
\hline WT (total) & 41 & 68.3 & 0 & & 41 & 67.2 \\
\hline WT (call: WT) & 35 & 58.3 & & & 35 & \\
\hline WT (call: potential low level mutation) & 6 & 10.0 & 0 & & 6 & \\
\hline Mutant & 19 & 31.7 & 1 & 100.0 & 20 & 32.8 \\
\hline Analysis failed & 1 & 1.6 & 0 & & & \\
\hline \multirow[t]{2}{*}{ Concordance of Results } & \multicolumn{2}{|c|}{ HRM } & \multicolumn{2}{|c|}{ Pyrosequencing } & & \\
\hline & $\mathrm{n}$ & $\%$ & $n$ & $\%$ & & \\
\hline Number of samples & 57 & 100 & 57 & 100 & & \\
\hline WT (total) & 38 & 66.7 & 37 & 64.9 & & \\
\hline WT (call: WT) & & & 33 & 57.9 & & \\
\hline WT (call: potential low level mutation) & & & 4 & 7.0 & & \\
\hline Mutant & 19 & 33.3 & 20 & 35.1 & & \\
\hline Concordant & 56 & 98.2 & & & & \\
\hline Discordant & 1 & 1.8 & & & & \\
\hline Correctly classified WT & 37 & 97.4 & & & & \\
\hline Incorrectly classified WT & 1 & 2.6 & & & & \\
\hline Correctly classified mutant & 19 & 100 & & & & \\
\hline Incorrectly classified mutant & 0 & 0 & & & & \\
\hline
\end{tabular}

the detection limit of the Nanodrop spectrophotometer not necessarily prevented successful HRM analysis. In contrast to HRM, the pyrosequencing assay had to be repeated for only one sample (Table 1 ). Thus, the failure rate of a first analysis run as a consequence of technical and/or sample-issues was significantly higher for HRM analysis than for pyrosequencing $(p=0.0042)$. Together, pyrosequencing is technically more reliable than HRM due to lower input requirements and a lower incidence of invalid results.

\section{Concordance of HRM and pyrosequencing results}

In order to evaluate the diagnostic validity of HRM analysis as a basic test for KRAS mutation detection, we compared the results from this assay to pyrosequencing in the 57 samples that could be successfully analysed by both methods. KRAS status was assigned concordantly for 56 samples $(98.2 \%$; kappa $=0.961)$, while the result for one sample with a low mutant allele frequency of $13.4 \%$ (\#3, Table 1) was inconsistent between HRM and pyrosequencing (Tables 1 and 2). Importantly, pyrosequencing indicated the presence of potential low level mutations (mutant allele frequency<4.0-5.2 \%, cf. Table 1) in four samples that were called WT by HRM. Given that this output is generated due to low signal strength for the potential mutation near the technical detection limit of the pyrosequencing method we finally classified these samples as WT. Conversely, all 19 samples that were clearly identified as mutant by HRM were classified identically by pyrosequencing. Therefore, defining pyrosequencing as the reference method, the specificity of HRM for detection of mutant KRAS alleles 
was $100 \%$. On the other hand, the specificity for the detection of WT alleles was slightly reduced (97.4\%) due to erroneous interpretation of the HRM curve for the one sample mentioned (\#3, Table 1) with a mutant allele frequency only slightly above the sensitivity threshold of the method. When we applied a different HRM assay for the detection of NRAS codon 61 mutations on an independent set of 19 CRC samples, we found a $100 \%$ concordance of results with reports from a reference laboratory (Additional file 1: Table S1). Of note, sensitivity of the NRAS HRM assay was comparable to the KRAS assay and allowed for reliable identification of mutations at a mutant sample fraction of $20 \%$ (Additional file 2: Figure S1). Taken together, these findings indicate that HRM represents a very reliable basic method for KRAS mutation testing.

Two-step KRAS mutation testing in routine diagnostics To evaluate the actual effectiveness of our two-step analysis platform (Fig. 3) in a routine diagnostic setting, we reviewed effort and outcome of KRAS codon 12/13 mutation testing in 120 independent colorectal cancer

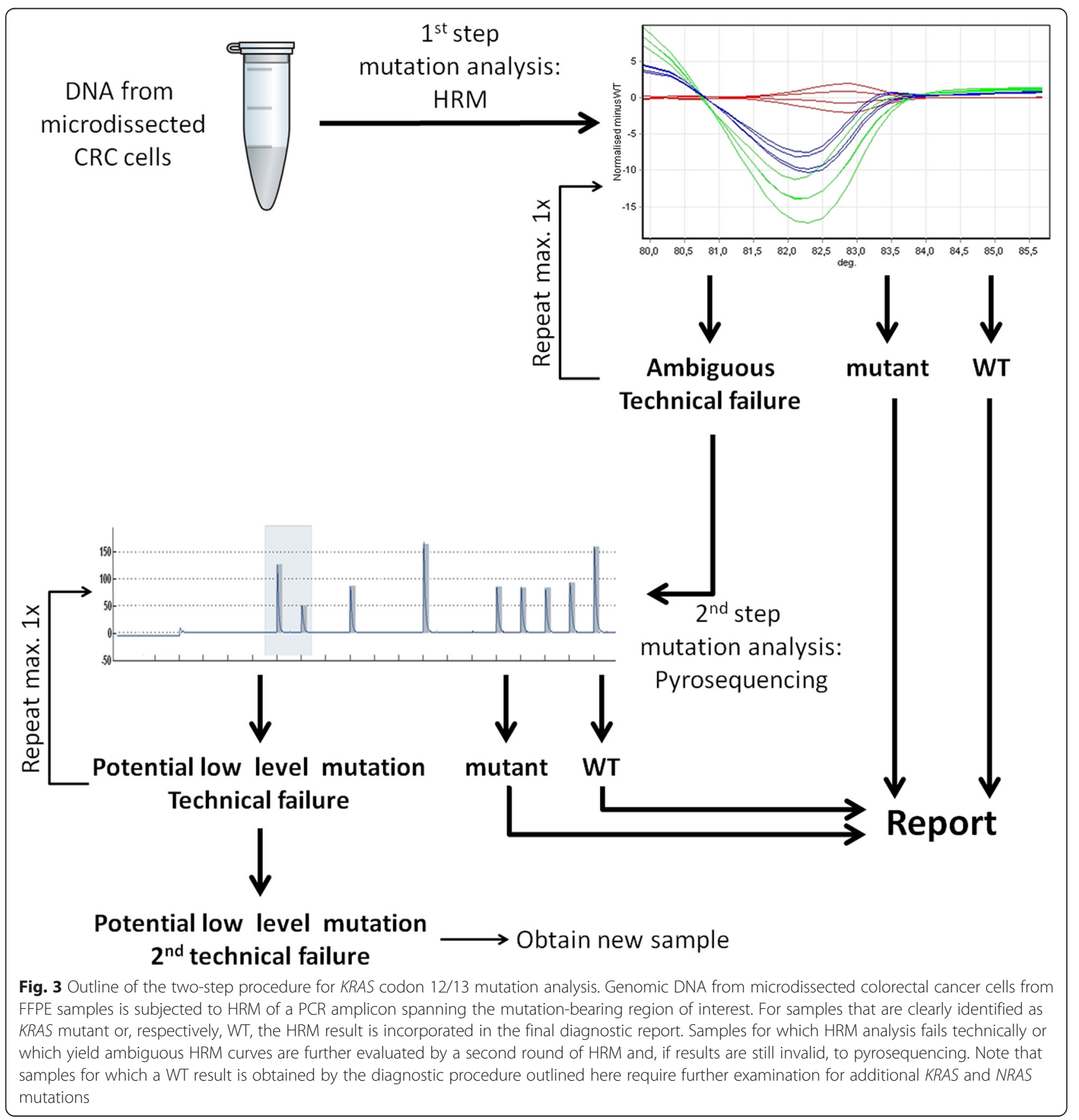


Table 3 Detailed results of KRAS codon 12/13 mutation testing in 120 CRC samples

\begin{tabular}{|c|c|c|c|c|c|c|c|}
\hline \multirow[b]{3}{*}{ Sample } & \multirow[b]{3}{*}{$\begin{array}{l}C_{D N A} \\
{[n g / \mu l]}\end{array}$} & \multicolumn{2}{|l|}{ HRM } & \multicolumn{4}{|c|}{ Pyrosequencing } \\
\hline & & \multirow[b]{2}{*}{$\begin{array}{l}\text { Run } \\
1\end{array}$} & \multirow[b]{2}{*}{$\begin{array}{l}\text { Run } \\
2\end{array}$} & \multicolumn{2}{|l|}{ Run 1} & \multicolumn{2}{|l|}{ Run 2} \\
\hline & & & & Result & $\begin{array}{l}\text { \% mut. } \\
\text { Alleles }\end{array}$ & Result & $\begin{array}{l}\% \text { mut. } \\
\text { Alleles }\end{array}$ \\
\hline 62 & 541 & $W T^{a}$ & & WT & & & \\
\hline 63 & 29 & $W T^{a}$ & & WT & & & \\
\hline 64 & 378 & WT & & & & & \\
\hline 65 & 342 & $W T^{a}$ & WT & & & & \\
\hline 66 & 176 & failed & $W T^{a}$ & G12V & 3.2 & G12V & 5.2 \\
\hline 67 & 139 & mut & & & & & \\
\hline 68 & 520 & WT & & & & & \\
\hline 69 & 42 & WT & & & & & \\
\hline 70 & 202 & WT & & & & & \\
\hline 71 & 157 & mut & & & & & \\
\hline 72 & 259 & mut & & & & & \\
\hline 73 & 145 & WT & & & & & \\
\hline 74 & 21 & failed & failed & WT & & & \\
\hline 75 & 22 & failed & & WT & & & \\
\hline 76 & 66 & mut & & & & & \\
\hline 77 & 55 & mut & & & & & \\
\hline 78 & 199 & mut & & & & & \\
\hline 79 & 197 & WT & & & & & \\
\hline 80 & 171 & WT & & & & & \\
\hline 81 & 55 & failed & & G12V & 41.1 & & \\
\hline 82 & 231 & failed & & WT & & & \\
\hline 83 & 250 & failed & & WT & & & \\
\hline 84 & 57 & failed & $W T^{a}$ & & & & \\
\hline 85 & 21 & mut & & & & & \\
\hline 86 & 248 & WT & & & & & \\
\hline 87 & 258 & WT & & & & & \\
\hline 88 & 83 & failed & & failed & & failed & \\
\hline 89 & 38 & failed & & WT & & & \\
\hline 90 & 279 & WT & & & & & \\
\hline 91 & 122 & failed & & WT & & & \\
\hline 92 & 129 & failed & & $\begin{array}{l}\text { Low } \\
\text { Mut. }\end{array}$ & 5.2 & $\begin{array}{l}\text { Low } \\
\text { Mut. }\end{array}$ & 8.2 \\
\hline 93 & 58 & WT & & & & & \\
\hline 94 & 129 & WT & & & & & \\
\hline 95 & 254 & WT & & & & & \\
\hline 96 & 373 & WT & & & & & \\
\hline 97 & 158 & WT & & & & & \\
\hline 98 & 96 & mut & & & & & \\
\hline 99 & 22 & WT & & & & & \\
\hline 100 & 30 & mut & & & & & \\
\hline 101 & 26 & $\mathrm{mut}^{\mathrm{a}}$ & $\mathrm{mut}^{\mathrm{a}}$ & G13D & 7.3 & & \\
\hline
\end{tabular}

Table 3 Detailed results of KRAS codon 12/13 mutation testing in 120 CRC samples (Continued)

\begin{tabular}{llll}
\hline 102 & 49 & WT & WT \\
103 & 47 & WT & WT
\end{tabular}

$\begin{array}{lllll}103 & 47 & \text { WT } & \text { WT }\end{array}$

10443 WT WT

10554 WT WT

106363 failed mut mut

$\begin{array}{llllll}\text { WT } & 106 & 363 & \text { failed } & \text { mut } & \text { mut } \\ \text { WT } & 107 & 521 & \text { failed } & \text { WT } & \text { WT }\end{array}$

WT

WT $108 \quad 199$ mut mut

$\begin{array}{lllll}\text { WT } & 109 & 260 & \text { WT } & \text { WT }\end{array}$

$\begin{array}{lllll}\text { mut } & 110 & 67 & \text { WT } & \text { WT }\end{array}$

$\begin{array}{lllll}\text { WT } & 111 & 103 & \text { WT } & \text { WT }\end{array}$

WT $112 \quad 24$ mut mut

WT $113 \quad 150$ WT

mut $114 \quad 5 \quad$ WT $\quad$ WT

$\begin{array}{llll}\text { mut } & 115 & 25 & \text { WT }\end{array}$

$\begin{array}{lllll}\text { WT } & 116 & 33 & \text { WT }\end{array}$

WT $117 \quad 26$ mut mut

$\begin{array}{lllll}\text { WT } & 118 & 72 & \text { WT } & \text { WT }\end{array}$

mut $\quad 119 \quad 16$ failed G12V 12.8 mut

$\begin{array}{lllll}\text { mut } & 120 & 33 & \text { failed } & \text { WT }\end{array}$

$\begin{array}{lllll}\text { mut } & 121 & 48 & \text { WT } & \text { WT }\end{array}$

$\begin{array}{lllll}\text { WT } & 122 & 74 & \text { WT } & \text { WT }\end{array}$

WT $123 \quad 474$ mut mut

mut $124 \quad 431$ mut mut

WT $125 \quad 66$ mut mut

WT $126 \quad 143$ mut mut

$\begin{array}{lllll}\text { WT } & 127 & 49 & \text { failed WT }\end{array}$

$\begin{array}{lllll}\text { mut } & 128 & 143 & \text { WT } & \text { WT }\end{array}$

WT $129 \quad 122$ mut mut

$\begin{array}{lllll}\text { WT } & 130 & 139 & \text { WT } & \text { WT }\end{array}$

$\begin{array}{llllll}\text { N/A } & 131 & 21 & \text { failed } & \text { WT } & \text { WT }\end{array}$

$\begin{array}{llllll}\text { WT } & 132 & 39 & \text { failed } & \text { WT } & \text { WT }\end{array}$

$\begin{array}{llllll}\text { WT } & 133 & 128 & \text { failed } & \text { G12D } & 26.7\end{array}$

WT $134 \quad 60$ mut mut

mut 135330 failed mut mut

$136 \quad 165$ mut mut

WT $137 \quad 213$ mut mut

WT $138 \quad 31$ failed mut mut

WT $139 \quad 156$ mut mut

$\begin{array}{lllll}\text { WT } & 140 & 59 & \text { WT } & \text { WT }\end{array}$

$\begin{array}{lllll}\text { WT } & 141 & 68 & \text { WT } & \text { WT }\end{array}$

$\begin{array}{lllll}\text { mut } & 142 & 164 & \text { WT } & \text { WT }\end{array}$

WT $143 \quad 238$ mut mut

mut $144 \quad 12$ mut mut

$\begin{array}{llllll}\text { mut } & 145 & 33 & \text { failed WT }\end{array}$ 
Table 3 Detailed results of KRAS codon 12/13 mutation testing in 120 CRC samples (Continued)

\begin{tabular}{|c|c|c|c|}
\hline 146 & 81 & WT & WT \\
\hline 147 & 11 & WT & WT \\
\hline 148 & 13 & mut & mut \\
\hline 149 & 71 & WT & WT \\
\hline 150 & 11 & mut & mut \\
\hline 151 & 40 & failed WT & WT \\
\hline 152 & 50 & WT & WT \\
\hline 153 & 128 & mut & mut \\
\hline 154 & 146 & WT & WT \\
\hline 155 & 69 & WT & WT \\
\hline 156 & 182 & WT & WT \\
\hline 157 & 32 & failed WT & WT \\
\hline 158 & 142 & WT & WT \\
\hline 159 & 53 & WT & WT \\
\hline 160 & 91 & failed WT & WT \\
\hline 161 & 334 & WT & WT \\
\hline 162 & 86 & failed WT & WT \\
\hline 163 & 61 & WT & WT \\
\hline 164 & 64 & WT & WT \\
\hline 165 & 141 & WT & WT \\
\hline 166 & 271 & WT & WT \\
\hline 167 & 40 & WT & WT \\
\hline 168 & 34 & failed WT & WT \\
\hline 169 & 29 & failed failed WT & WT \\
\hline 170 & 354 & WT & WT \\
\hline 171 & 66 & WT & WT \\
\hline 172 & 43 & failed WT & WT \\
\hline 173 & 114 & WT & WT \\
\hline 174 & 268 & WT & WT \\
\hline 175 & 107 & WT & WT \\
\hline 176 & 170 & mut & mut \\
\hline 177 & 65 & failed mut & mut \\
\hline 178 & 31 & failed mut & mut \\
\hline 179 & 61 & WT & WT \\
\hline 180 & 659 & mut & mut \\
\hline 181 & 34 & WT & WT \\
\hline
\end{tabular}

a Skewed HRM curve

samples that were examined consecutively in our laboratory according to this concept (Table 3). We found, that KRAS status could be determined for $87.5 \%$ of samples by HRM and for $99.2 \%$ of samples in total, when pyrosequencing was applied to samples that could not be successfully analysed by HRM (Table 4). However, for both HRM and pyrosequencing, the failure rate was slightly higher than anticipated based on the observations from our initial 61 sample set (Tables 2 and 4). Also of note, the number of samples that were subjected to pyrosequencing in routine diagnostics exceeded the previously estimated need of this analysis $(19 / 120=$ $15.5 \%$ vs. $4 / 61=6.6 \%$ ) because 15 samples were directly analysed by pyrosequencing after the first failed HRM run in order to utilize otherwise wasted capacities. Yet, in summary, these data strongly support the rationale of our two-step approach to KRAS codon 12/13 mutation analysis, confirming the accuracy of our diagnostic platform.

\section{Assay costs}

In order to estimate the economic benefits of our twostep approach to KRAS mutation testing, we compared analysis costs in our routine setting to a pyrosequencingonly platform. Based on current list prices for reagents and consumables, we estimated the assay costs for HRM analysis and pyrosequencing at approximately $€ 7.50$ and $€ 100$, respectively (Table 5). The costs for the essential technical devices for both methods have not been converted to per-sample costs because operation expenses are highly dependent on sample throughput, including not only the KRAS mutation assay but also other applications. Moreover, investments for technical equipment are in the same range for pyrosequencing and HRM. Considering the failure rates of each assay in our set of 120 routine samples (23.6\% for HRM and $9.1 \%$ for pyrosequencing), leading to repeated testing of some samples, our two-step approach allows for net reduction of operational costs of approximately $75 \%$ compared to pyrosequencing alone. Moreover, according to our experience, handson time for processing the maximum number of samples for one HRM-run $(14+4$ controls) is only half of the time required to prepare and perform a pyrosequencing run at full capacity $(22+2$ controls $)$ (Table 5). Therefore, our concept to maintain two sequential assays for KRAS codon 12/13 mutation testing represents cost- and time-effective approach for routine diagnostics.

\section{Discussion}

Here we present a two-step approach to KRAS codon 12/13 mutation testing for mCRC employing HRM analysis and pyrosequencing using the Therascreeen KRAS Pyro Kit. Comparing the performance of the two methods in a panel of 61 samples, we observed a $98.2 \%$ concordance of results with a $100 \%$ specificity of HRM for the detection of mutant alleles. Thus, HRM analysis needs methodically independent confirmation of results by pyrosequencing only in exceptional cases and therefore can serve as a filter assay to exclude clearly WT or mutant samples from the more expensive and more 
Table 4 Operational analysis of two-step KRAS mutation testing of 120 CRC samples

\begin{tabular}{|c|c|c|c|c|c|c|}
\hline \multirow[b]{2}{*}{ HRM } & \multicolumn{2}{|c|}{ Run 1} & \multicolumn{2}{|c|}{ Run 2} & \multicolumn{2}{|c|}{ Summary } \\
\hline & $n$ & $\%$ & $\mathrm{n}$ & $\%$ & $n$ & $\%$ \\
\hline Number of samples & 120 & 100.0 & 20 & $100.0(16.7)$ & 120 & 100.0 \\
\hline Analysis passed & 89 & 74.2 & 18 & 90.0 & 105 & 87.5 \\
\hline WT (total) & 60 & 67.4 & 12 & 66.7 & 71 & 67.6 \\
\hline WT (skewed HRM curve) & 3 & 5.0 & 2 & 16.7 & 4 & 5.6 \\
\hline Mutant (total) & 29 & 32.6 & 6 & 33.3 & 34 & 32.4 \\
\hline Mutant (skewed HRM curve) & 1 & 3.4 & 1 & 16.7 & 1 & 2.9 \\
\hline Analysis failed & 31 & 25.8 & 2 & 10.0 & & \\
\hline Pyrosequencing & $n$ & $\%$ & $\mathrm{n}$ & $\%$ & $\mathrm{n}$ & $\%$ \\
\hline Number of samples & 19 & $100.0(15.8)$ & 3 & $100.0(2.5)$ & 19 & 100.0 \\
\hline Analysis passed & 18 & 94.7 & 2 & 66.7 & 18 & 94.7 \\
\hline WT & 12 & 66.7 & 0 & 0.0 & 13 & 72.2 \\
\hline Potential low level mutation & 2 & 11.1 & 1 & 50.0 & 0 & 0.0 \\
\hline Mutant & 4 & 22.2 & 1 & 50.0 & 5 & 27.8 \\
\hline Analysis failed & 1 & 5.3 & 1 & 33.3 & 1 & \\
\hline Combined HRM + Pyrosequencing & & & & & $n$ & $\%$ \\
\hline Number of samples & & & & & 120 & 100.0 \\
\hline Number of HRM runs & & & & & 140 & 116.7 \\
\hline Number of pyrosequencing runs & & & & & 22 & 18.3 \\
\hline Analysis passed & & & & & 119 & 99.2 \\
\hline WT & & & & & 81 & 68.1 \\
\hline Mutant & & & & & 38 & 31.9 \\
\hline Analysis failed & & & & & 1 & 0.8 \\
\hline
\end{tabular}

laborious pyrosequencing analysis. Specifically, based on our observations reported here, this approach can reduce throughput of the pyrosequencing assay by $>85 \%$, resulting in a $>75 \%$ cost reduction compared to using pyrosequencing only. We emphasize, that our comparison of the two methods in the first place aimed on diagnostic accuracy for sequential application in order to

Table 5 Per-sample costs and hands-on time for HRM and pyrosequencing analyses

\begin{tabular}{lll}
\hline & HRM & Pyrosequencing \\
\hline Costs (Euro) & & \\
Reagents & 3.40 & 90.00 \\
Consumables & 2.40 & 3.50 \\
Controls & 1.70 & 8.50 \\
Total & 7.50 & 102.00 \\
Time (minutes) & & \\
14 samples +4 controls & 60 & 120 \\
22 samples +2 controls & &
\end{tabular}

Costs for the controls were estimated based on the maximum number of samples that can be processed in one HRM- or pyrosequencing run, respectively. Costs for HRM controls also include DNA isolation from KRAS WT and mutant cell lines. Hands-on time is indicated for full capacity runs establish a reliable and economized platform for KRAS mutation testing. Of note, we reached this goal in spite we were able to detect mutant KRAS alleles only at a frequency $>12.5 \%$ instead of $5 \%$ as reported in the literature $[20,26]$.

With respect to technical performance, although we successfully applied HRM to very low input samples, we state a clear advantage for the pyrosequencing assay due to lower input requirements and an apparently relatively high susceptibility of HRM to artifacts. More precisely, previous authors have pointed out, that especially WT HRM curves show a certain degree of variation resulting from poor quality of FFPE-derived template DNA, differing salt- or inhibitor concentrations or unspecific amplification [20,27], that may complicate correct determination of KRAS status. Consistent with this notion, 6 of the 7 samples in our 61sample validation set that were subjected to a second round of HRM analysis due to poor interpretability of first round results were eventually called WT by this method. Conversely, we did not obtain false positive results by HRM, i.e., none of our samples that had been identified as mutant by HRM was found to be WT according to pyrosequencing. Yet, we state that the mutation frequency of 
KRAS codon 12/13 observed in our study was slightly lower than reported in the literature $[9,10]$, which may be explained by our homogenous patient population from a single center (Marburg, Germany).

Concerning diagnostic value of results from our sequential KRAS mutation analysis procedure, it is important to point out that pyrosequencing results include information on the site, type and frequency of the nucleotide exchange, while HRM only allows for categorical discrimination of WT and mutant tumors. According to current standards, such a dual output is actually sufficient to establish the indication for antiEGFR treatment, although certain authors have suggested that not all KRAS mutations are equal regarding outcome in mCRC patients treated with cetuximab [3]. Consequently, as clinical routine testing at present in principle does not require sequence-based analysis, the more differentiated output of the pyrosequencing assay does not warrant the higher costs for this analysis. Therefore, the two-step procedure for KRAS mutation testing presented here represents a reasonable diagnostic approach not only from a technical-practical and economical, but also from a clinical perspective. More specifically, using our diagnostic platform focused on KRAS codon 12/13 mutation testing, even small diagnostic laboratories can provide accurate and clinically meaningful results within a short processing time for the most relevant genetic alteration that determines a treatment decision for mCRC patients. Consequently, only a small fraction of patient samples has to be sent to an external reference laboratory for further molecular studies in accordance with the current EMA standards and recommendations by the American Society of Clinical Oncology, which state that Ras mutation testing prior to initiation of treatment with cetuximab and panitumumab has to include analysis of both KRAS and NRAS exons 2, 3 and 4 (codons 12, 13, 59, 61, 117 and 146). Also of note, besides KRAS and NRAS mutations, alterations in several other genes such as BRAF and PIK3CA have been proposed to predict outcome with EGFR antibody treatment [28-30]. Thus, identification of patients eligible for cetuximab or panitumumab treatment in fact requires either a broad panel of single mutation tests or a multiplex approach. Optimized methods for DNA melting analysis of short PCR amplicons have been suggested to allow for comprehensive hot spot mutation testing in a clinical setting as they require only standard qPCR equipment. However, each assay requires careful optimization, implying considerable efforts for a diagnostic laboratory to set up all tests on site [31]. Alternatively, next generation sequencing (NGS) with a targeted resequencing approach appears to be a suitable technology for extensive clinically relevant mutation testing in the future, which has already been evaluated for the molecular diagnostics of colorectal cancer [32, 33]. Given the high frequency of KRAS codon $12 / 13$ mutations compared to other KRAS- or NRAS mutations and the fact that these mutations occur mutually exclusive [10], it still seems reasonable, to filter the samples that actually need advanced testing method as proposed here. Thus, a two-step approach including HRM analysis of KRAS codon 12/13 mutations followed by next generation targeted resequencing might be the most attractive implementation for routine KRAS mutation diagnostics in the future.

\section{Conclusion}

We present a diagnostically reliable and cost-effective two-step approach to KRAS codon 12/13 mutation testing of CRC samples prior to initiation of treatment with antiEGFR antibodies. The platform appears to be especially attractive for small to medium diagnostic laboratories that don't have the capacities to maintain an extensive spectrum of rare mutation tests according to regulatory standards for diagnostic laboratories [34] or to adopt NGS-technology with its complex associated infrastructure including bioinformatics.

\section{Additional files}

Additional file 1: Supplementary method and Table S1. HRM analysis of NRAS codon 61 and Results of NRAS codon 61 mutation testing in 19 CRC samples. (DOCX $22 \mathrm{~kb}$ )

Additional file 2: Figure S1. HRM analysis of NRAS codon 61 (TIF $553 \mathrm{~kb}$ )

\section{Abbreviations}

CRC, colorectal cancer; EMA. European medical agency; FDA, U.S. food and drug administration; HRM, high resolution melting analysis; LOD, limit of detection; $\mathrm{mCRC}$, metastatic colorectal cancer; NGS, next generation sequencing; PCR, polymerase chain reaction; qPCR, quantitative polymerase chain reaction; WT, wildtype; UICC, Union internationale contre le cancer.

\section{Acknowledgements}

We like to thank Viktoria Wischmann, Department of Pathology, University Hospital Marburg for microdissection of CRC specimens. Petra Ross, Lisa-Marie Koch and the staff of the Molecular Biology Laboratory, Department of Hematology and Oncology are acknowledged for excellent technical assistance and helpful discussion.

\section{Funding}

This work was supported by DFG Klinische Forschergruppe KFO210 (AN, CB) and the José Carreras Leukemia Foundation (AH06-01, to AN).

\section{Availability of data and materials}

The dataset supporting the conclusions of this article is included within the article and its supplementary material.

\section{Authors' contributions}

$\mathrm{CB}, \mathrm{EM}$ and RM conceived and designed the study. RM reviewed tissue sections. KS established the method and performed KRAS mutation analysis. $\mathrm{KS}, \mathrm{CB}$ and EM analysed data. AN and JRK contributed to the analysis and interpretation of the data. EM wrote the manuscript, which was critically revised by $C B, A N, R M$ and JRK. All authors read and approved the final manuscript. 


\section{Competing interests}

The authors declare that they have no competing interests.

\section{Consent for publication}

Not applicable.

\section{Ethics approval and consent to participate}

This study was conducted in a routine diagnostic setting for internal quality control purposes and did not require formal ethics approval according to the guidelines of the local ethics comitee. Verbal informed consent to perform routine pathological examinations on their samples as needed was obtained from all patients.

\section{Author details}

${ }^{1}$ Klinik für Hämatologie, Onkologie und Immunologie, Universitätsklinikum Gießen und Marburg, Standort Marburg, Philipps-Universität Marburg Baldingerstraße, Marburg, Germany. ${ }^{2}$ Institut für Pathologie, Universitätsklinikum Gießen und Marburg, Standort Marburg, Philipps-Universität Marburg, Baldingerstraße, Marburg, Germany.

Received: 7 July 2016 Accepted: 20 July 2016

Published online: 02 August 2016

\section{References}

1. Jemal A, Bray F, Center MM, Ferlay J, Ward E, Forman D. Global cancer statistics. CA Cancer J Clin. 2011;61(2):69-90.

2. Stein $A$, Bokemeyer $C$. How to select the optimal treatment for first line metastatic colorectal cancer. World J Gastroenterol. 2014;20(4):899-907.

3. De Roock W, Jonker DJ, Di Nicolantonio F, Sartore-Bianchi A, Tu D, Siena S, Lamba S, Arena S, Frattini M, Piessevaux H, et al. Association of KRAS p.G13D mutation with outcome in patients with chemotherapy-refractory metastatic colorectal cancer treated with cetuximab. JAMA. 2010;304(16):1812-20.

4. De Roock W, Piessevaux H, De Schutter J, Janssens M, De Hertogh G, Personeni N, Biesmans B, Van Laethem JL, Peeters M, Humblet Y, et al. KRAS wild-type state predicts survival and is associated to early radiological response in metastatic colorectal cancer treated with cetuximab. Ann Oncol. 2008:19(3):508-15.

5. Di Fiore F, Blanchard F, Charbonnier F, Le Pessot F, Lamy A, Galais MP, Bastit $\mathrm{L}$, Killian A, Sesboue R, Tuech JJ, et al. Clinical relevance of KRAS mutation detection in metastatic colorectal cancer treated by Cetuximab plus chemotherapy. Br J Cancer. 2007:96(8):1166-9.

6. Douillard JY, Oliner KS, Siena S, Tabernero J, Burkes R, Barugel M, Humblet Y, Bodoky G, Cunningham D, Jassem J, et al. Panitumumab-FOLFOX4 treatment and RAS mutations in colorectal cancer. N Engl J Med. 2013; 369(11):1023-34

7. Karapetis CS, Khambata-Ford S, Jonker DJ, O'Callaghan CJ, Tu D, Tebbutt NC, Simes RJ, Chalchal H, Shapiro JD, Robitaille S, et al. K-ras mutations and benefit from cetuximab in advanced colorectal cancer. N Engl J Med. 2008; 359(17):1757-65.

8. Lievre A, Bachet JB, Boige V, Cayre A, Le Corre D, Buc E, Ychou M, Bouche $\mathrm{O}$, Landi $\mathrm{B}$, Louvet $\mathrm{C}$, et al. KRAS mutations as an independent prognostic factor in patients with advanced colorectal cancer treated with cetuximab. J Clin Oncol. 2008;26(3):374-9.

9. Normanno N, Tejpar S, Morgillo F, De Luca A, Van Cutsem E, Ciardiello F. Implications for KRAS status and EGFR-targeted therapies in metastatic CRC. Nat Rev Clin Oncol. 2009;6(9):519-27.

10. Vaughn CP, Zobell SD, Furtado LV, Baker CL, Samowitz WS. Frequency of KRAS, BRAF, and NRAS mutations in colorectal cancer. Genes Chromosomes Cancer. 2011:50(5):307-12.

11. 05/12/2014 Erbitux -EMEA/H/C/000558 -N/0071 - Erbitux : EPAR - Product Information [http://www.ema.europa.eu/docs/en_GB/document_library/ EPAR___Product_Information/human/000558/WC500029119.pdf]

12. 31/03/2015 Vectibix -EMEA/H/C/000741 -II/0065 - Vectibix: EPAR Product Information [http://www.ema.europa.eu/docs/en_GB/document_library/ EPAR_-_Product_Information/human/000741/WC500047710.pdf]

13. Label approved on 03/11/2015 (PDF) for VECTIBIX, BLA no. 125147 [http:// www.accessdata.fda.gov/drugsatfda_docs/label/2015/125147s200lbl.pdf]

14. Label approved on 04/10/2015 (PDF) for ERBITUX, BLA no. 125084 [http.// www.accessdata.fda.gov/drugsatfda_docs/label/2015/125084s262lbl.pdf]

15. Amado RG, Wolf M, Peeters M, Van Cutsem E, Siena S, Freeman DJ, Juan T, Sikorski R, Suggs S, Radinsky R, et al. Wild-type KRAS is required for panitumumab efficacy in patients with metastatic colorectal cancer. J Clin Oncol. 2008:26(10):1626-34.

16. List of Cleared or Approved Companion Diagnostic Devices (In Vitro and Imaging Tools) [http://www.fda.gov/MedicalDevices/ ProductsandMedicalProcedures/InVitroDiagnostics/ucm301431.htm]

17. Bolton L, Reiman A, Lucas K, Timms J, Cree IA. KRAS mutation analysis by PCR: a comparison of two methods. PLoS One. 2015;10(1):e0115672.

18. Gonzalez De Castro D, Angulo B, Gomez B, Mair D, Martinez R, Suarez Gauthier A, Shieh F, Velez M, Brophy VH, Lawrence HJ, et al. A comparison of three methods for detecting KRAS mutations in formalin-fixed colorectal cancer specimens. Br J Cancer. 2012;107(2):345-51.

19. Heideman DA, Lurkin I, Doeleman M, Smit EF, Verheul HM, Meijer GA, Snijders PJ, Thunnissen E, Zwarthoff EC. KRAS and BRAF mutation analysis in routine molecular diagnostics: comparison of three testing methods on formalin-fixed, paraffin-embedded tumor-derived DNA. J Mol Diagn. 2012; 14(3):247-55

20. Krypuy M, Newnham GM, Thomas DM, Conron M, Dobrovic A. High resolution melting analysis for the rapid and sensitive detection of mutations in clinical samples: KRAS codon 12 and 13 mutations in nonsmall cell lung cancer. BMC Cancer. 2006;6:295.

21. Sakai K, Tsurutani J, Yamanaka T, Yoneshige A, Ito A, Togashi Y, De Velasco MA, Terashima M, Fujita Y, Tomida S, et al. Extended RAS and BRAF Mutation Analysis Using Next-Generation Sequencing. PLoS One. 2015;10(5): e0121891.

22. Tuononen K, Maki-Nevala S, Sarhadi VK, Wirtanen A, Ronty M, Salmenkivi K, Andrews JM, Telaranta-Keerie Al, Hannula S, Lagstrom S, et al. Comparison of targeted next-generation sequencing (NGS) and real-time PCR in the detection of EGFR, KRAS, and BRAF mutations on formalin-fixed, paraffinembedded tumor material of non-small cell lung carcinoma-superiority of NGS. Genes Chromosomes Cancer. 2013;52(5):503-11.

23. Herreros-Villanueva M, Chen CC, Yuan SS, Liu TC, Er TK. KRAS mutations: analytical considerations. Clin Chim Acta. 2014;431:211-20.

24. Wittwer CT, Reed GH, Gundry CN, Vandersteen JG, Pryor RJ. High-resolution genotyping by amplicon melting analysis using LCGreen. Clin Chem. 2003; 49(6 Pt 1):853-60.

25. Ronaghi $M$, Uhlen $M$, Nyren P. A sequencing method based on real-time pyrophosphate. Science. 1998;281(5375):363. 365.

26. Qiagen: Therascreen ${ }^{\circledR}$ KRAS Pyro ${ }^{\oplus}$ Kit handbook version 1, German edition. Hilden, Germany: Qiagen; 2011.

27. Do H, Dobrovic A. Dramatic reduction of sequence artefacts from DNA isolated from formalin-fixed cancer biopsies by treatment with uracil- DNA glycosylase. Oncotarget. 2012;3(5):546-58.

28. De Roock W, Claes B, Bernasconi D, De Schutter J, Biesmans B, Fountzilas G, Kalogeras KT, Kotoula V, Papamichael D, Laurent-Puig P, et al. Effects of KRAS, BRAF, NRAS, and PIK3CA mutations on the efficacy of cetuximab plus chemotherapy in chemotherapy-refractory metastatic colorectal cancer: a retrospective consortium analysis. Lancet Oncol. 2010;11(8):753-62.

29. Mao C, Yang ZY, Hu XF, Chen Q, Tang JL. PIK3CA exon 20 mutations as a potential biomarker for resistance to anti-EGFR monoclonal antibodies in KRAS wild-type metastatic colorectal cancer: a systematic review and metaanalysis. Ann Oncol. 2011;23(6):1518-25.

30. Sorich MJ, Wiese MD, Rowland A, Kichenadasse G, McKinnon RA, Karapetis CS. Extended RAS mutations and anti-EGFR monoclonal antibody survival benefit in metastatic colorectal cancer: a meta-analysis of randomized, controlled trials. Ann Oncol. 2015:26(1):13-21.

31. Botezatu IV, Nechaeva IO, Senderovich Al, Kondratova VN, Shelepov VP, Lichtenstein AV, Stroganova capital A CEMC. Optimization of melting analysis with TaqMan probes for detection of KRAS, NRAS, and BRAF mutations. Anal Biochem. 2015;491:75-83.

32. Betge J, Kerr G, Miersch T, Leible S, Erdmann G, Galata CL, Zhan T, Gaiser T, Post S, Ebert MP, et al. Amplicon sequencing of colorectal cancer: variant calling in frozen and formalin-fixed samples. PLoS One. 2015;10(5):e0127146.

33. Malapelle U, Vigliar E, Sgariglia R, Bellevicine C, Colarossi L, Vitale D, Pallante $\mathrm{P}$, Troncone $\mathrm{G}$. Ion Torrent next-generation sequencing for routine identification of clinically relevant mutations in colorectal cancer patients. J Clin Pathol. 2015;68(1):64-8.

34. Allegra CJ, Rumble RB, Hamilton SR, Mangu PB, Roach N, Hantel A, Schilsky RL. Extended RAS Gene Mutation Testing in Metastatic Colorectal Carcinoma to Predict Response to Anti-Epidermal Growth Factor Receptor Monoclonal Antibody Therapy: American Society of Clinical Oncology Provisional Clinical Opinion Update 2015. J Clin Oncol. 2016;34(2):179-85. 